\title{
Leprosy: Current status in a Tertiary Care Hospital after 65 Years of Different National Leprosy Control Programs in India
}

\author{
Archana Chintaman Choure*, Rajeev Kishor Saxena and \\ Sachinkumar Vasantrao Wankhede \\ Department of Microbiology, Smt. Kashibai Navale Medical College and \\ General Hospital, Pune, India \\ *Corresponding author
}

\section{A B S T R A C T}

\section{Keywords}

Leprosy (Hansen's disease), NTD

(Neglected Tropical Disease), Current status, Slit skin smear (SSS) \& India

\section{Article Info}

\section{Accepted:}

15 December 2020 Available Online: 10 January 2021
Many infectious diseases are prevalent in India, but after the emergence of HIV/AIDS, the due importance has not been given to leprosy and hence neglected by medical researchers' and government bodies. Leprosy (Hansen's disease) is one of the Neglected Tropical Diseases (NTDs) in India. On the occasion of World first Neglected Tropical Disease Day i.e. January 30, 2020 this motivated us to study status of leprosy in our institute retrospectively. To diagnose leprosy by slit skin smears (SSS) examination and profiling of leprosy patients in a tertiary care hospital. Total 446 slit skin smears were examined from Jan 2015 to Dec 2019for leprosy diagnosis by following standard microbiological methods. Among all clinically suspected patients $75.8 \%$ were IPD patients. Among all clinically suspected leprosy patients $10.9 \%$ were positive by Slit Skin Smear (SSS) examination. SSS positive leprosy patients were more during year 2017. There was male predominance $(67.3 \%)$ among all SSS positive leprosy patients. Total 59\% SSS positive leprosy patients were from urban area. Leprosy is still prevalent in India after 65 years of different national leprosy control programs. It is the need of hour for medical fraternity to screen patients actively for leprosy. Early diagnosis and treatment is the key to reduce the prevalence, so high index of suspicion is required. Each and every infectious disease has its own impact on community health so all infectious diseases to be given equal importance for early diagnosis, treatment and prevention by medical researchers and government bodies. These approaches will reduce the burden of leprosy as a Neglected Tropical Disease in India.

\section{Introduction}

Despite advances in all fields of health science, leprosy continues to be a major public health challenge in developing countries like India ${ }^{1}$. Leprosy is caused by Mycobacterium lepareand very well known in history since long time ${ }^{2}$ :
Vedic times in India (described as KushthaRoga in SushrutaSamhita, 600 BC).

Biblical times in the Middle East

Hippocrates, 460 BC.

G. H. Armauer Hansen (1873) in Norway discovered Mycobacterium lepare. It was first 
bacterial pathogen to humans but still it remains one of the least understood bacteria because of it's non-cultivable nature. However Shepard (1960) was able to multiply these bacteria in footpad of mouse ${ }^{2}$.

India's major 11 NTDs (Neglected Tropical Diseases) are Ascariasis, Hookworm disease, Trichuriasis, Dengue, Lymphatic Filariasis, Trachoma, Cysticercosis, Leprosy, Ehinococcosis, Visceral Leishmaniasis and Rabies. ${ }^{3}$ Leprosy (Hansen's disease) is one of the Neglected Tropical Diseases (NTDs) in India. According to WHO, India may account for more than one-half of the global prevalent and new cases of leprosy. ${ }^{4}$

In Maharashtra, it is found that very few districts within the state or very few pockets within the district are actually having leprosy burden. It is more in Vidarbha region followed by Rest of Maharashtra and Marathwada. ${ }^{5}$ On the occasion of World first Neglected Tropical Disease Day i.e. January 30, 2020 we have been motivated to study current status of leprosy in our Institute retrospectively. This paper will focus onleprosy cases in a tertiary care hospital located in Rest of Maharashtra.

The main objectives of this study include to diagnose leprosy by doing slit skin smears (SSS) examination And also to study the profile of leprosy patients visiting a tertiary care hospital.

\section{Materials and Methods}

This study was done in the Department of Microbiology, Smt. Kashibai Navale Medical College and General Hospital, Pune. Aretrospective study was done on leprosy patients.Total 446 slit skin smears were examined for diagnosis of leprosy during the period from Jan 2015 to Dec 2019.

Slit skin smears were prepared by collecting skin, ear lobe\& eyebrows specimens from six sites of clinically suspected leprosy patients. These smears were stained by ZiehlNeelsentechnique by using 5\% sulfuric acid for decolorization. Under oil immersion objective, red acid fast bacilli arranged singly or in groups (cigar like bundles) were observed. $^{2}$ All SSS positive patient details were entered in MS EXCEL sheet and data related to gender, OPD/IPD and area wise distribution was studied and compiled in graphs and charts for analysis.

\section{Results and Discussion}

Among all clinically suspected leprosy patients $75.8 \%$ were IPD patients (Table-1).

Among all clinically suspected leprosy patients $10.9 \%$ were positive by Slit Skin Smear (SSS) examination (Table-2).

SSS positive leprosy patients were more during year 2017 (Table-3).

There was male predominance $(67.3 \%)$ among all SSS positive leprosy patients (Table-4).

Total 59\% SSS positive leprosy patients were from urban area (Table-5).

India experiencesthe world's largest absolute burden of at least 11 major NTDs. Excluding NTDs that arespatially bound by their requirement for unique insect vectors or snail hosts (e.g., schistosomiasis,onchcocerciasis, human African trypanosomiasis, and Chagas disease), India leads the world in terms of the total number of cases for each of the major NTDs, as defined by theWorld Health Organization (WHO).Ascariasis, Hookworm disease, Trichuriasis, Dengue, Lymphatic Filariasis, Trachoma, Cysticercosis, Leprosy, Ehinococcosis, Visceral Leishmaniasis and Rabies are the major NTDs in India. ${ }^{3}$ 
Table.1 Distribution of clinically suspected leprosy patients visiting a tertiary care hospital

\begin{tabular}{|c|c|c|c|}
\hline Year & OPD Patients(\%) & IPD Patients(\%) & Total Patients $(\mathbf{\% = 4 4 6 )}$ \\
\hline $\mathbf{2 0 1 5}$ & 22 & 87 & 109 \\
\hline $\mathbf{2 0 1 6}$ & 23 & 89 & 112 \\
\hline $\mathbf{2 0 1 7}$ & 23 & 29 & 52 \\
\hline $\mathbf{2 0 1 8}$ & 12 & 70 & 82 \\
\hline $\mathbf{2 0 1 9}$ & 28 & 63 & 91 \\
\hline Total & $108(24.2)$ & $338(75.8)$ & 446 \\
\hline
\end{tabular}

Table.2 Distribution of leprosy patients diagnosed by slit skin smear examination

\begin{tabular}{|c|c|c|}
\hline Year & $\begin{array}{c}\text { Clinically Suspected Leprosy } \\
\text { Patients }(\mathbf{n = 4 4 6 )}\end{array}$ & $\begin{array}{c}\text { Diagnosed By Slit Skin Smear } \\
\text { Examination (\%) }\end{array}$ \\
\hline $\mathbf{2 0 1 5}$ & 109 & 9 \\
\hline $\mathbf{2 0 1 6}$ & 112 & 13 \\
\hline $\mathbf{2 0 1 7}$ & 52 & 15 \\
\hline $\mathbf{2 0 1 8}$ & 82 & 4 \\
\hline $\mathbf{2 0 1 9}$ & 91 & 8 \\
\hline TOTAL & 446 & $49(10.9)$ \\
\hline
\end{tabular}

Table.3 Distribution of leprosy patients diagnosed by slit skin smear (SSS) examination

\begin{tabular}{|c|c|c|c|}
\hline Year & OPD Patients & IPD Patients & Total SSS Positive \\
\hline $\mathbf{2 0 1 5}$ & 0 & 9 & 9 \\
\hline $\mathbf{2 0 1 6}$ & 1 & 12 & 13 \\
\hline $\mathbf{2 0 1 7}$ & 2 & 13 & 15 \\
\hline $\mathbf{2 0 1 8}$ & 0 & 4 & 4 \\
\hline $\mathbf{2 0 1 9}$ & 3 & 5 & 8 \\
\hline Total & 6 & 43 & 49 \\
\hline
\end{tabular}

Table.4 Gender distribution of all SSS POSITIVE patients

\begin{tabular}{|c|c|c|c|}
\hline Year & Male (\%) & Female $(\boldsymbol{\%})$ & Total(n=49) \\
\hline $\mathbf{2 0 1 5}$ & 7 & 2 & 9 \\
\hline $\mathbf{2 0 1 6}$ & 8 & 5 & 13 \\
\hline $\mathbf{2 0 1 7}$ & 11 & 4 & 15 \\
\hline $\mathbf{2 0 1 8}$ & 1 & 3 & 4 \\
\hline $\mathbf{2 0 1 9}$ & 6 & 2 & 8 \\
\hline Total & $33(67.3)$ & $16(32.7)$ & 49 \\
\hline
\end{tabular}




\section{Fig.1}

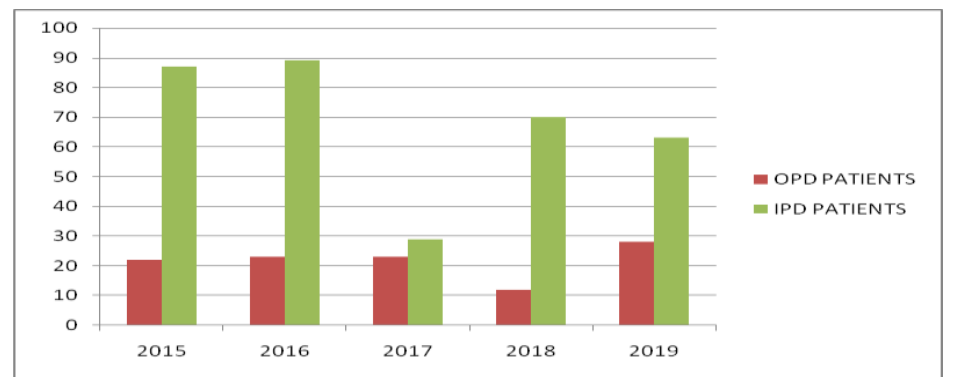

Among all clinically suspected patients $75.8 \%$ were IPD patients

Fig.2

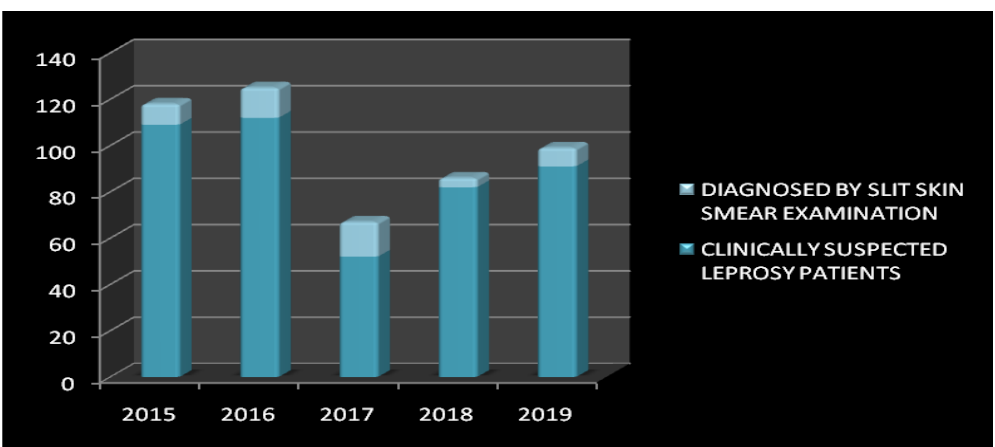

Among all clinically suspected leprosy patients $10.9 \%$ were positive by Slit Skin Smear (SSS) examination

Fig.3

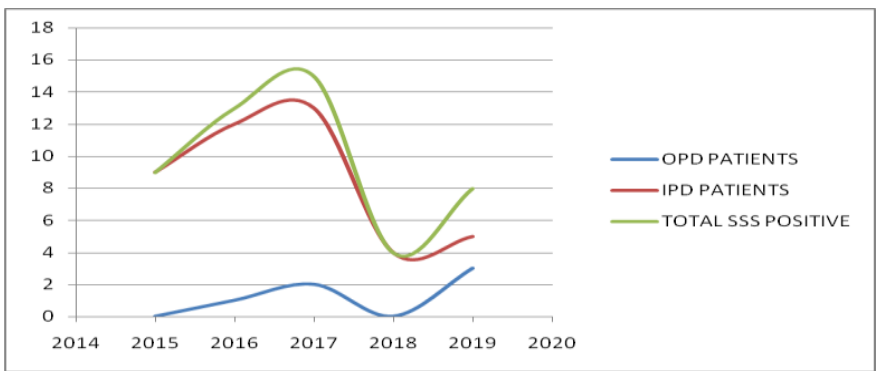

SSS positive leprosy patients were more during year 2017

Fig.4

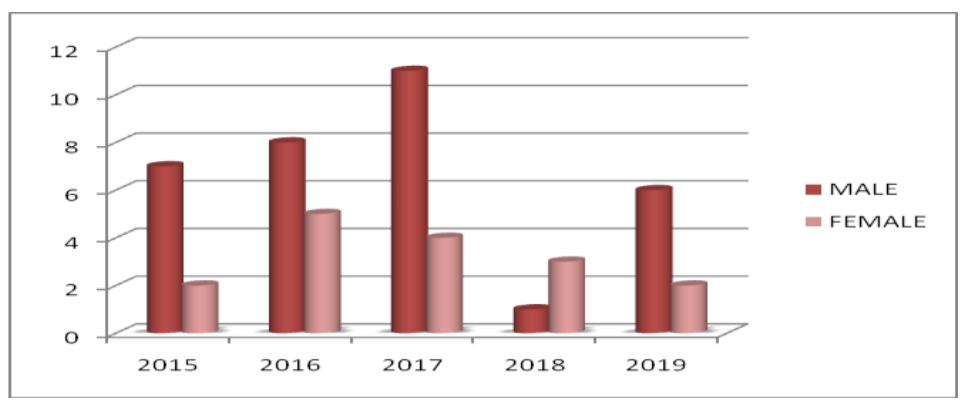

There was male predominance $(67.3 \%)$ among all SSS positive leprosy patients 
Fig.5 Area wise distribution of all SSS POSITIVE patients

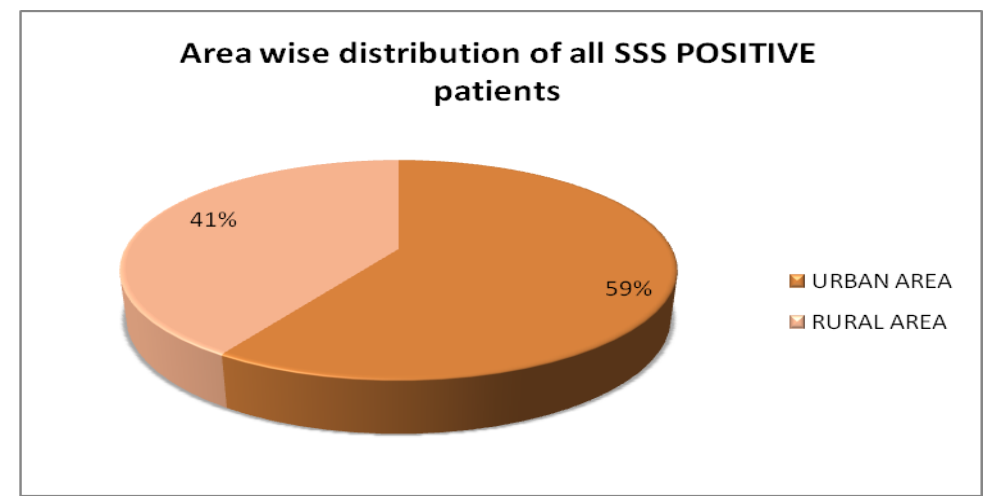

Total 59\% SSS positive leprosy patients were from urban area

Leprosy is chronic infectious disease of skin and neurons, caused by Mycobacterium leprae and Mycobacterium lepromatosis. The global leprosy status has changed significantly over the last four decades after the initiation of multidrug therapy (MDT) in 1982 with a reduction in prevalence from over 5 million cases in the mid-1980s to less than 200,000 at the end of 2016. ${ }^{1}$ The WHO launched a 5-year "Global leprosy strategy 2016- 2020' in April 2016 titled 'Accelerating towards a leprosy-free world'. Strategy for years 2016-2020 was based on three pillars: (i) to strengthen government ownership, coordination, and partnership; (ii) to stop leprosy and its complications; and (iii) to stop discrimination and promote inclusion ${ }^{1}$ 6. NLEP (National Leprosy Elimination Programme) had introduced the Mycobacterium indicus Prani (MiP) vaccine in a project mode in India from the year 2016.

MIP vaccine has been shown to have both immunotherapeutic and immune-prophylactic effects in multibacillary leprosy patients and their contacts in both hospital and population-based trials. It also reduced the bacillary load, upgraded the lesions histopathologically, led to complete clearance of granuloma, reduced reactions, and neuritis. $^{1,7,8}$
M. leprae is a nonmotile, non-sporeforming, microaerophilic, acid-fast-staining bacterium that usually forms slightly curved or straight rods. $M$. leprae is non-cultivable but can be maintained in axenic cultures in what appears to be stable metabolic state for a few weeks. As a result, propagation of $M$. leprae has been restricted to only animal models, including the armadillo and normal, athymic, and gene knockout mice. These methods have provided the basic information for genetic, metabolic, and antigenic studies of the bacillus. Growth of $M$. leprae in mouse footpads also provides a tool for testing the drug susceptibility of clinical isolates. ${ }^{9-13}$ Tilldate Slit Skin Smear examination is the mainstay for diagnosis of leprosy patients.

In our study it was observed that among all clinically suspected leprosy patients, $75.8 \%$ were IPD patients (Table-1). Among all clinically suspected leprosy patients $10.9 \%$ were positive by Slit Skin Smear (SSS) examination (Table-2). It indicates the screening of all patients was actively done for leprosy diagnosis. India, Brazil and Indonesia were the countries where leprosy new cases were more than 10,000 per year. During 2017 India accounted for $66 \%$ of total cases globally. ${ }^{14}$ In other words, two out of every three new global leprosy cases are detected in India. 
The proportion of child cases was $8.7 \%$ at national level and $10.18 \%$ in Maharashtra during 2017. ${ }^{14}$ Our study reflected that all $10.9 \%$ (49 patients) SSS positive leprosy cases were from adult age group, but surprisingly not a single case from children age group. It suggests that active screening of cases to be done in pediatric patients also.

In Maharashtra, a total of 15,498 new cases diagnosed, of these $8325 \mathrm{MB}, 6770$ (43\%) were women and 1912 (12\%) were children. Even within state of Maharashtra better performing districts like Satara and Pune (with PR around 0.5/10,000) showing genderwise, urban-rural area wise, MB cases-wise disparities. ${ }^{15-17}$ Our observation was that leprosy patients were more during year 2017 and least number of cases were during 2018(Table-3). There was male predominance (67.3\%) among all SSS positive leprosy patients (Table-4). Bhattacharya et $\mathrm{al}^{18} \&$ Mathan $\mathrm{R}$ et al., ${ }^{19}$ also observed higher incidence in male patients. Ramos et $\mathrm{al}^{20}$ reported $64.5 \%$ male, $35.6 \%$ female and $3.2 \%$ children leprosy cases in their seven and half year study.

Leprosy, a NTD primarily affect the poorest sectors of society, especially the rural poor and the most disadvantaged urban populations. $^{21,22}$ The present study showed $59 \%$ leprosy patients were from urban area (Table-5).

The year 2020 was a crucial year for the future global response on NTDs. It was expected that the progress against the 2020 NTD roadmap targets will be assessed and new 2021-2030 NTD roadmap will be launched by $\mathrm{WHO}^{23}$ Unfortunately the pandemic of SARS CoV-2 disturbed all calculations of researchers, as the number of new cases of COVID-19 infection increases, the incidence of leprosy reactions may also increase considerably. ${ }^{24}$
In conclusion,

Leprosy is still prevalent in India after 65 years of different national leprosy control programs. It is the need of hour for medical fraternity to screen patients actively for leprosy.

Early diagnosis and treatment is the key to reduce the prevalence, so high index of suspicion is required.

Each and every infectious disease has its own impact on community health so all infectious diseases to be given equal importance for early diagnosis, treatment and prevention by medical researchers and government bodies.

These approaches will reduce the burden of leprosy as a Neglected Tropical Disease in India.

\section{Acknowledgement}

All authors are thankful to entire department of skin and dermatology for sending samples for Slit Skin Smear examination for diagnosis of leprosy.

\section{References}

1. Rao PN, Suneetha S. Current situation of leprosy in India and its future implications. Indian Dermatol Online $\mathbf{J}$ 2018; 9:83-9.

2. ApurbaS Sastry, SandhyaBhat. Mycobacteria, Essentials of Medical Microbiology. $2^{\text {nd }}$ Ed. New Delhi: Jaypeebrothers' medical Publishers (P) Ltd; 2019.p.296-302.

3. Hotez PJ, Damania A (2018) India's neglected tropical diseases. PLoSNegl Trop Dis 12 (3): e0006038.https://doi.org/10.1371/journal.

4. World Health Organization (2017) Global leprosy update, 2016: accelerating reduction of disease burden. Weekly Epidemiol Rec 92(35) 501-20.

5. Katkar D, Mote BN, Adhav A, Muthuvel 
T, Kadam S. Epidemiological perspective of National Leprosy Eradication Programme in Maharashtra: Focusing on "Tribal Hot-spot" of Tribal District. Indian J Community Med 2017; 42:174-6.

6. Global leprosy strategy 2016-2020: Accelerating towards a leprosy-free world. New Delhi, World Health Organization, Regional Office for South-East Asia; 2016.

7. Sharma P, Kar HK, Misra RS, Mukherjee A, Kaur H,Mukherjee R, Rani R. Mycobacterium $\mathrm{W}$ vaccine, a usefuladjuvant to multidrug therapy in multi-bacillary leprosy: A report on hospital based immunotherapeutic clinical trials with afollow-up of 1-7 years after treatment. Lepr Rev 2000:71:179-92.

8. Sharma P, Mukherjee R, Talwar GP, Sarathchandra KG, Walia R,Parida SK, et al. Immunoprophylactic effects of the anti-leprosyMw vaccine in household contacts of leprosy patients:Clinical field trials with a follow up of 8-10 years. Lepr Rev2005:76:127-43.

9. D. M. Scollard, * L. B. Adams, T. P. Gillis, J. L. Krahenbuhl,R. W. Truman, and D. L. Williams. The Continuing Challenges of Leprosy. CLINICAL MICROBIOLOGY REVIEWS, Apr. 2006; 19:2 p. 338-381.

10. Krahenbuhl, J. L., and L. B. Adams. 2000. Exploitation of gene knockoutmice models to study the pathogenesis of leprosy. Lepr. Rev. 71:S170-S175.

11. Shepard, C. C., and Y. T. Chang. 1962. Effect of several anti-leprosy drugson multiplication of human leprosy bacilli in footpads of mice. Proc. Soc.Exp. Biol. Med. 109:636-638.

12. Truman, R. W., and J. L. Krahenbuhl. 2001. Viable M. leprae as a research reagent. Int. J. Lepr. Other Mycobact. Dis. 69:1-12.

13. Truman, R. 2005. Leprosy in wild armadillos. Lepr. Rev. 76:198-208.
14. Oommen C. Kurian. Leprosy and Inequities in India's Healthcare: Beyond the Persistent Rhetoric of 'Elimination'. ORF occasional paper \# 184 february 2019.

15. Dhananjay Katkar, BaluNatha Mote, Ambadas Adhav, Thirumugam Muthuvel and Suhas Kadam. Epidemiological Perspective of National Leprosy Eradication Programme in Maharashtra: Focusing on "Tribal Hot-spot" of Tribal District Indian J Community Med. 2017 Jul-Sep; 42(3): 174-176.

16. Mohite RV, Mohite VR, Durgawale PM. Differential trend of leprosy in rural and urban area of Western Maharashtra. Indian J Lepr. 2013; 85:11-8.

17. World Health Organization. Scale up Efforts against Leprosy; Focus on Preventing Disabilities in Children. World Health Organization. 2017.

18. Bhattacharya SN, Sehgal VN. Leprosy in India. ClinDermatol 1999; 17:159-70.

19. Mathan R, Devan KM. Incidence and Clinical Profile of Leprosy in a Tertiary Care Hospital: A Retrospective Study. Int J Sci Stud 2016; 4(3):178-179.

20. Ramos et al.: Gender differential on characteristics and outcome of leprosy patients admitted to a long-term care rural hospital in South-Eastern Ethiopia. International Journal for Equity in Health 2012 11:56.

21. Liese B, Rosenberg M, Schratz A. Programmes, partnerships and governance for elimination and control of neglected tropical diseases. Lancet 2010; 375: 67-76.

22. Jai P Narain, AP Dash, B Parnell, SK Bhattacharya, S Barua, R Bhatia \& L Savioli. Elimination of neglected tropical diseases in the South-East Asia Region of the World Health Organization. Bulletin of the World Health Organization 2010; 88:206-210.

23. Dirk Engels, and Xiao-Nong Zhou. Neglected tropical diseases: an effective 
global response to local poverty-related disease priorities. Engels and Zhou Infectious Diseases of Poverty (2020) 9:10.

24. Antunes DE, Goulart IMB, Goulart LR
(2020) Will cases of leprosy reaction increase with COVID-19 infection? PLoSNegl Trop Dis 14(7): e0008460.

\section{How to cite this article:}

Archana Chintaman Choure, Rajeev Kishor Saxena and Sachinkumar Vasantrao Wankhede. 2021. Leprosy: Current status in a Tertiary Care Hospital after 65 Years of Different National Leprosy Control Programs in India. Int.J.Curr.Microbiol.App.Sci. 10(01): 2419-2426. doi: https://doi.org/10.20546/ijcmas.2021.1001.280 